\title{
Healthcare providers' perception of advance care planning for patients with critical illnesses in acute-care hospitals: a cross-sectional study
}

Kanako Yamamoto ${ }^{1,2^{*}}$,, Yuki Yonekura ${ }^{1,2}$ and Kazuhiro Nakayama²

\begin{abstract}
Background: In acute-care hospitals, patients treated in an ICU for surgical reasons or sudden deterioration are treated in an outpatient ward, ICU, and other multiple departments. It is unclear how healthcare providers are initiating advance care planning (ACP) for such patients and assisting them with it. The purpose of this study is to clarify healthcare providers' perceptions of the ACP support provided to patients receiving critical care in acute-care hospitals.

Methods: A cross-sectional study was conducted using questionnaires. In this study, 400 acute-care hospitals with ICUs in Japan were randomly selected, and 1490 subjects, including intensivists, surgeons, ICU nurses, surgical floor nurses, and surgical outpatient nurses, participated. Survey items examined whether ICU patients received ACP support, the participants' degree of confidence in providing ACP support, the patients' treatment preferences, and the decision-making process, and whether any discussion was conducted on change of values.

Results: Responses were obtained from 598 participants from 157 hospitals, 41.4\% of which reportedly supported ACP provision to ICU patients. The subjects with the highest level of ACP understanding were surgeons (45.8\%), and differences in understanding were observed across specialties $(P<0.001)$. Among the respondents, physicians and nurses expressed high levels of confidence in providing ACP support to patients requiring critical care. However, $15.2 \%$ of all the subjects mentioned that they would not attempt to resuscitate the patients. In addition, $25.7 \%$ of the participants handed over patients'values to other departments or hospitals, whereas $25.3 \%$ handed over the decisionmaking process.
\end{abstract}

Conclusions: Among the participating hospitals, 40\% provided ACP support to patients receiving critical care. The low number is possibly because support providers lack understanding of the content of patients' ACP or about how to support and use ACP. Second, it is sometimes too late to start providing ACP support after ICU admission. Third, healthcare providers differ in their perception of ACP, widely considered an ambiguous concept. Finally, in acutecare hospitals with different healthcare settings, it is necessary to confirm and integrate the changes in feelings and thoughts of patients.

Keywords: Acute-care hospital, Advance care planning, Critical care, Intensive care unit, Advance directives

${ }^{*}$ Correspondence: ykanako@slcn.ac.jp

2 Department of Nursing Informatics, Graduate School of Nursing Science, St. Luke's International University, 10-1, Akashi-cho, Tokyo, Japan Full list of author information is available at the end of the article

\section{Background}

Patients receiving critical care often experience the sudden onset of life-threatening symptoms. Advance care planning (ACP) empowers patients in the final stage of their lives to spend their days according to their wishes. 
Advance care planning can include advance directives (ADs) as for example do not attempt resuscitation (DNAR) and living wills. ACP is a process that concretises ADs by discussing patients' wishes regarding treatment, values, goals, and preferences [1]. There are differences in the way various countries approach the $\mathrm{ACP}$ and how they respond to the wishes of patients. In Europe and the United States, the wishes of patients are protected by law through the documentation of ADs. In Japan, however, the ACP is only a recommendation in the guidelines and is not legally enforceable [2].

Previous ACP studies have been conducted in patients with advanced cancer and in elderly patients living in nursing homes [3, 4]. However, currently, only inadequate ACP support is provided to patients treated in intensive care units (ICUs) $[5,6]$. This may be the result of the unclear boundary between life-saving and life-prolonging strategies in the critical care process. In addition, it is challenging to discuss ACP among ICU patients, because the ICU is widely considered a place to receive life-saving treatment [7]. In general, the goal of ACP is quality end-of-life care. It is considered that predicting the patient's prognosis and understanding that the patient is in the terminal stage will lead to the initiation or promotion of ACP support for the patient. However, one of the problems faced by intensive care physicians is in an accurate prediction of such patients' prognoses [8]. It is reported that $50-60 \%$ of patients with DNAR in the ICU remained alive till their discharge $[9,10]$. This suggests that aggressive treatment may not be futile, even in patients whose recovery may be deemed difficult. In addition, healthcare providers remain indifferent to ACP because the ICU may be widely recognized as a place to provide life-saving treatment.

Moreover, since the ICU is where patients undergoing sudden changes in their disease conditions are treated, it is difficult in many cases to confirm the patients' wishes regarding treatment, and the implementation of ACP in the ICU is complex too. ICU patients are often incapable of making decisions themselves, and a surrogate decisionmaker is required to provide the necessary explanation and consent for DNAR [11-13]. Therefore, healthcare providers and surrogate decision-makers often have compelling reasons to decide on transition from lifesaving to end-of-life medical care without any information on the patient's wishes; the DNAR order speeds up this transition [14-16]. Another reason for the difficulty in supporting ACP for patients treated in acute-care hospitals and ICUs is the involvement of multiple practitioners. Patients who receive temporary surgical treatment or emergency transport at an acute-care hospital likely have more than one primary care physician, as well as multiple attending physicians, at the hospital. Moreover, patients with multiple diseases receive treatment from more than one expert physician. A study on patients with poor outcomes admitted to the ICU revealed conflicts among intensivists, ICU nurses, cardiovascular surgeons, cardiothoracic surgeons, and neurosurgeons in determining the patients' treatment goals [17]. In this study, $60 \%$ of intensivists and surgeons had conflicting opinions about determining patients' end-of-life care preferences. One reason for the conflict is the unique ICU management system, with more than one physician making decisions about a patient's treatment. In some circumstances, the provision of ACP support to ICU patients, which usually involves only the patient and their primary physician, differs significantly from the recommended process. An essential aspect of ACP is the process in which surrogate decision-makers and healthcare providers discuss and share DNAR and ADs regarding how patients live, what they value, and what they desire [18]. However, among patients receiving critical care, the discussion in which healthcare providers and patients share treatment values is difficult, and DNAR decisions are often the main focus [13-16]. Further, in acute-care hospitals, critically ill patients are treated by multiple healthcare providers, and treatments of a patient are generally not confined to the outpatient, general ward, and ICU settings. In such hospitals, the manner in which a healthcare provider confirms and takes over a patient's wishes is considered an important aspect of the patient's treatment process. However, to date, no studies have clarified the status of ACP support provided to patients receiving critical care from the perspectives of multiple occupations and departments. By clarifying these findings, one may realise important ways to support the provision of patientcentred care to such patients in acute-care hospitals. In addition, it may be possible to clarify how to support patients based on their treatment processes and the continuity of their care. Thus, the purpose of this study is to clarify healthcare providers' perception of ACP support for patients receiving critical care in acute-care hospitals.

\section{Methods \\ Study design}

A cross-sectional study was conducted in acute-care hospitals with ICUs in Japan. The current study is a sub-study on decision-making support in acute-care hospitals with ICUs in Japan, focusing on how ACP support and discussion start for patients receiving critical care in acute-care hospitals. As part of the study, a survey was carried out by distributing an anonymous self-reported questionnaire during August to December 2019. 


\section{Participants}

The criteria for participant selection were as follows: (1) physicians working in an ICU as an intensive care specialist, (2) surgeons providing consultations to the ICU during the perioperative period (cardiovascular surgeons, thoracic surgeons, gastrointestinal surgeons, neurosurgeons, etc.), (3) nurses with at least 3 years of ICU experience, (4) nurses with at least 3 years of experience working in surgical wards, and (5) nurses with at least 3 years of experience working in surgical outpatient clinics. Participants meeting any of the following criteria were excluded: (1) resident physicians and (2) nurses in their first or second year of employment.

In this study, statistical data were analysed using analysis of variance. An estimated correlation ratio of 0.05 and a detection power of 0.8 were set, and a total of 350 subjects, with 70 subjects from each department (ICU, Surgical, Outpatient), were considered as the target sample. The research targeted 400 randomly selected hospitals with ICUs in Japan under a 30\% response rate assumption. Therefore, approximately 1-3 physicians, 5 ICU nurses, 5 surgical floor nurses and 1-3 surgical outpatient nurses were sampled per facility. We asked the director of a hospital to cooperate in this study The number of samples were a total of 1520 comprising 240 fulltime intensivists, 240 surgeons, 400 ICU nurses, 400 floor nurses, and 240 outpatient nurses. Of these, the following were granted informal consent for surveys: 155 intensivists, 127 surgeons, 555 ICU nurses, 422 floor nurses, and 231 outpatient nurses and a total of 170 hospitals. The total number was 1490 .

\section{Data collection and statistical analysis}

Data collection was carried out by mailing a survey request form and a sample questionnaire to the managers of each department of the target hospitals. The facilities recruited were added in the order in which the survey approval was obtained, and the questionnaire was sent to the participants. Next, the questionnaire with a return envelope were sent to the participants. The survey's purpose and method and the treatment of personal information were explained in writing to each participant. After completing the questionnaire, the participants sealed the envelope and sent it back by post.

\section{Survey questionnaire development}

A questionnaire was developed for this study, with reference to guidelines on end-of-life medical treatment of emergency/critical care in Japan [18] and to the educational material for healthcare providers on ACP [19]. The questionnaires included questions testing the participants' knowledge of $\mathrm{ACP}$ and the current status of support for ACP in their respective hospitals. The appropriateness of the items was discussed and assessed by the authors of this study. Regarding the easy-to-answer questionnaire, about 10 healthcare providers were asked to answer it (Additional file 1). The main outcomes of this survey clarified whether or not ACP support was provided to prospective ICU patients. Besides, questions of the survey examined how to obtain consent for DNAR, how often to obtain confirmation, how and when to confirm the wishes of prospective ICU patients, how to collaborate with other departments and institutions, and knowledge of ACP. Participants' basic attributes, such as their age, gender, years of work experience, and designation, were also collected.

Physicians and nurses were asked to describe their professional qualifications, while floor nurses and outpatient nurses noted the department to which they belonged, and ICU nurses, intensivists, and surgeons were asked to categorise the ICU management system they operated within. The ICU management systems were categorized into the following three groups for the purpose of this study: (1) A closed-ICU is a facility where only intensivists make decisions on all the patients' treatment strategies. (2) In a semi-ICU, intensivists intervene for all patients in the ICU or for patients in need (they work with the patient's primary physician). (3) An ICU without an intensivist was called an open-ICU (open format ICU).

\section{Data analysis}

IBM SPSS Statistics Ver. 25.0 software was used for statistical analysis. After basic statistical analysis, normality was confirmed and descriptive statistics were performed. The difference in perceptions by occupation and the average difference between departments were obtained. Further, the existence of any significant difference among five participants having different occupations and belonging to various departments was examined using one-way analysis of variance.

Tukey's multiple comparison test was performed whenever significant differences less than $5 \%$ were found. Further, when equal group variance could not be assumed, Welch's test was performed, and when a significant difference at $<5 \%$ was observed, Game-Howell's multiple comparisons were performed. The t-test was conducted to analyse two groups with different occupations and departments. Finally, the $\chi^{2}$ test was performed for the nominal scale, and the significance level was set as $<5 \%$ (two-sided test). All statistical analyses were performed by supervising statisticians. 


\section{Ethical considerations}

Participants were provided written explanations of the survey's purpose, research methods used, details of participating in and withdrawing from the survey, protection of personal information, and data management methods used in the study. The collected data were managed separately, and ID numbers and a correspondence table were created to ensure that individual participants could not be identified from the data. Further, data such as basic attributes were coded to maintain participant anonymity. Since participation was anonymous and voluntary, the completed questionnaires sent in by participants themselves were considered as consent.

\section{Results}

\section{Participant overview}

Completed questionnaires were returned by 124 intensivists (response rate, $80.0 \%$ ), 59 surgeons (46.5\%), $183 \mathrm{ICU}$ nurses (33.0\%), 123 floor nurses (29.1\%), and 109 outpatient nurses (47.2\%) in 157 institutions (92.4\%). Table 1 summarises the demographic details of participants. Most of the participants belonged to the semi-closed ICU management system (210 participants or 57.4\%). From the surgery departments, 23 (39.0\% of the total) cardiovascular surgeons, 22 (37.3\%) gastrointestinal surgeons, and $10(16.9 \%)$ neurosurgeons participated in the study.

\section{Healthcare professionals' perception of ACP support}

As depicted in Tables 2, 25 intensivists (20.2\%), 9 surgeons (15.3\%), $22 \mathrm{ICU}$ nurses (12.0\%), 14 floor nurses (11.4\%), and 17 outpatient nurses (15.6\%) reported having provided ACP support to patients in, or before entering, the ICU. In addition, 65 of the 157 participating hospitals offered ACP support to patients. Although there was no common characteristic among the prominent participants in each job category, intensivists and

Table 1 Demographic details of survey respondents

\begin{tabular}{|c|c|c|c|c|c|c|c|c|c|c|}
\hline \multirow[t]{2}{*}{ Characteristic } & \multicolumn{2}{|l|}{ Intensivist } & \multicolumn{2}{|l|}{ Surgeon } & \multicolumn{2}{|l|}{ ICU nurse } & \multicolumn{2}{|c|}{ Floor nurse } & \multicolumn{2}{|c|}{$\begin{array}{l}\text { Outpatient } \\
\text { nurse }\end{array}$} \\
\hline & $\mathbf{n}$ & $\%$ & $\mathbf{n}$ & $\%$ & $\mathrm{n}$ & $\%$ & $\mathbf{n}$ & $\%$ & $\mathbf{n}$ & $\%$ \\
\hline \multicolumn{11}{|l|}{ Gender } \\
\hline Male & 106 & 85.5 & 57 & 96.6 & 51 & 27.9 & 14 & 11.4 & 2 & 1.8 \\
\hline Female & 18 & 14.5 & 2 & 3.4 & 132 & 72.1 & 109 & 88.6 & 107 & 98.2 \\
\hline \multicolumn{11}{|l|}{ Position } \\
\hline Manager & 38 & 30.6 & 17 & 28.8 & 14 & 7.7 & 17 & 13.8 & 12 & 11 \\
\hline Chief & 28 & 22.6 & 20 & 33.9 & 29 & 15.8 & 19 & 15.4 & 13 & 11.9 \\
\hline Staff & 58 & 46.8 & 22 & 37.3 & 140 & 76.5 & 87 & 70.7 & 85 & 77.1 \\
\hline \multicolumn{11}{|l|}{ Clinical department } \\
\hline Gastroenterology & & & 22 & 37.3 & & & 67 & 54.5 & 38 & 34.9 \\
\hline Cardiovascular & & & 23 & 39.0 & & & 31 & 25.2 & 38 & 34.9 \\
\hline Thoracic surgery & & & 3 & 5.1 & & & & & & \\
\hline Neurosurgery & & & 10 & 16.9 & & & 16 & 13.0 & 21 & 19.2 \\
\hline Other & & & 1 & 1.7 & & & 9 & 5.1 & 12 & 11.0 \\
\hline \multicolumn{11}{|l|}{ Specialist qualifications } \\
\hline Certified nurse & & & & & 19 & 10.4 & 17 & 13.8 & 13 & 11.9 \\
\hline Certified nurse specialist & & & & & 5 & 2.7 & 6 & 4.9 & 2 & 1.8 \\
\hline Nurse practitioner & & & & & 1 & 0.5 & 0 & 0.0 & 0 & 0.00 \\
\hline None & & & & & 158 & 86.3 & 100 & 81.3 & 94 & 86.2 \\
\hline \multicolumn{11}{|l|}{ Type of ICU } \\
\hline Closed-ICU & 28 & 22.6 & 3 & 5.1 & 21 & 11.5 & & & & \\
\hline Semi-Closed ICU & 79 & 63.7 & 42 & 71.2 & 89 & 48.6 & & & & \\
\hline Open-ICU & 17 & 13.7 & 14 & 23.7 & 73 & 39.9 & & & & \\
\hline Age, mean $\pm S D$ & $45.7 \pm 10.0$ & & $46.3 \pm 9.4$ & & $35.3 \pm 7.3$ & & $35.6 \pm 8.6$ & & $42.9 \pm 7.8$ & \\
\hline Years of work experience, mean $\pm S D$ & $20.3 \pm 9.2$ & & $21.0 \pm 9.5$ & & $12.6 \pm 6.9$ & & $12.6 \pm 7.4$ & & $19.0 \pm 8.0$ & \\
\hline
\end{tabular}

ICU Intensive care unit; SD Standard deviation

NOTES. Total numbers of intensivists, $n=124$; surgeons, $n=59$; ICU nurses, $n=183$; floor nurses, $n=123$; outpatient nurses, $n=109$.

A closed ICU is a facility where only intensivists make decisions on all the treatment strategies for patients.

In semi-closed ICUs, intensivists intervene for all patients in the ICU or the patients in need.

An ICU without an intensivist is referred to as an open ICU 
Table 2 Status of the introduction of ACPs for patients in ICUs

\begin{tabular}{|c|c|c|c|c|c|c|c|c|c|c|c|}
\hline & \multicolumn{2}{|c|}{ Intensivist } & \multicolumn{2}{|c|}{ Surgeon } & \multicolumn{2}{|c|}{ ICU nurse } & \multicolumn{2}{|c|}{ Floor nurse } & \multicolumn{2}{|c|}{ Outpatient nurse } & \multirow[t]{2}{*}{$P$ value } \\
\hline & $\mathbf{n}$ & $\%$ & $\mathbf{n}$ & $\%$ & $\mathbf{n}$ & $\%$ & $\mathbf{n}$ & $\%$ & $\mathbf{n}$ & $\%$ & \\
\hline \multicolumn{12}{|l|}{ ACP support } \\
\hline I did. & 25 & 20.2 & 9 & 15.3 & 22 & 12 & 14 & 11.4 & 17 & 15.6 & 0.0189 \\
\hline \multicolumn{12}{|l|}{ Who supported the ACP? } \\
\hline Intensivists & 42 & 73.7 & 1 & 5.9 & 15 & 8.2 & 0 & 0.0 & 0 & 0.0 & \\
\hline Surgeons & 22 & 38.6 & 11 & 64.7 & 21 & 11.5 & 13 & 10.6 & 9 & 8.3 & \\
\hline Nurses & 7 & 12.3 & 2 & 11.8 & 30 & 16.4 & 6 & 4.9 & 3 & 2.8 & \\
\hline Palliative care team & 3 & 5.3 & 1 & 5.9 & 6 & 3.3 & 4 & 3.3 & 2 & 1.8 & \\
\hline \multicolumn{12}{|c|}{ Transition of patients' treatment preferences and decisions ${ }^{\text {a }}$} \\
\hline Medical information and discharge plans & 110 & 88.7 & 50 & 84.7 & 144 & 78.7 & 86 & 69.9 & 70 & 64.2 & $<0.001$ \\
\hline Treatment desired by the patient & 77 & 62.1 & 30 & 50.8 & 128 & 69.9 & 84 & 68.3 & 64 & 58.7 & 0.035 \\
\hline Desired place for recovery & 32 & 25.8 & 20 & 33.9 & 49 & 26.8 & 67 & 54.5 & 51 & 46.8 & $<0.001$ \\
\hline Patient's values, and something to live for & 32 & 25.8 & 8 & 13.6 & 50 & 27.3 & 31 & 25.2 & 33 & 30.3 & 0.218 \\
\hline Process leading to treatment decision & 37 & 29.8 & 8 & 13.6 & 54 & 29.5 & 27 & 22.0 & 26 & 23.9 & 0.081 \\
\hline Surrogate decision-maker & 48 & 38.7 & 10 & 16.9 & 65 & 35.5 & 38 & 30.9 & 19 & 17.4 & $<0.001$ \\
\hline I won't give you any information & 4 & 3.2 & 0 & 0.0 & 5 & 2.7 & 3 & 2.4 & 6 & 5.5 & 0.377 \\
\hline Other & 4 & 3.2 & 0 & 0.0 & 8 & 4.4 & 1 & 0.8 & 1 & 0.9 & \\
\hline
\end{tabular}

ICU Intensive care unit; ACPs Advance care plans

NOTES. Total numbers of intensivists, $n=124$; surgeons, $n=59$; ICU nurses, $n=183$; floor nurses, $n=123$; outpatient nurses, $n=109$.

a Include duplicate answer

surgeons were more prevalent than others. When asked what they said when ICU patients moved to general ward or outpatient, the most frequent answer was "medical information and discharge plans"; this was transitioned by $110(91.3 \%)$ intensivists, $50(84.7 \%)$ surgeons, and 144 (78.7\%) ICU nurses, while 32 (27.2\%) intensivists, 8 (13.6\%) surgeons, and 50 (27.3\%) ICU nurses transitioned their patients' life worth and values $(P=0.006)$.

The degree of understanding of the use of ACPs was strongest among intensivists (21\% "often understanding", 4\% "always understanding") $(P=0.097)$ (Table 3$)$. Further, 27 surgeons $(45.8 \%)$ were able to select the correct items for ACP knowledge, with a significant difference $(P<0.001)$. The degrees of confidence of various participants in supporting ACP provision to patients and their families were $48.8 \pm 26.5,46.9 \pm 27.7,34.6 \pm 22.7$, $38.5 \pm 21.3$, and $36.8 \pm 27.1$ for intensivists, surgeons, ICU nurses, floor nurses, and outpatient nurses, respectively $(P=0.016)$.

Further, several intensivists $(41,33.1 \%)$, surgeons $(23$, $39.0 \%)$, ICU nurses $(58,31.7 \%)$, floor nurses $(87,70.7 \%)$, and outpatient nurses $(76,69.7 \%)$ responded that the patient selected the surrogate decision-maker $(P=0.127)$ (Table 4). The most preferred surrogate decision-maker was someone from among the patient's family $(P<0.001)$. In addition, 20 intensivists (16.1\%), 8 surgeons (13.6\%), 21 ICU nurses (11.5\%), 32 floor nurses (26.0\%), and 10 outpatient nurses $(9.2 \%)$ said that patients could perform DNAR confirmation (often and always) $(p<.001)$. According to intensivists, surgeons, and ICU nurses, DNAR confirmation was commonly performed 'at the time of disease worsening. In addition, 32 intensivists (25.9\%), 11 surgeons (18.7\%), 53 ICU nurses (29.0\%), 12 floor nurses $(9.8 \%)$, and 8 outpatient nurses (7.3\%) agreed that re-discussed DNAR should be performed frequently, or absolutely, whenever the patient's condition changed $(P<.001)$.

\section{Provision of decision-making support to patients and performance of cross-departmental information-sharing by healthcare providers}

To the question whether patients admitted to the ICU might be asked about their wishes to receive treatment, 32 (25.8\%) intensivists, 11 (18.6\%) surgeons, and $64(35.0 \%)$ ICU nurses answered that the patients were asked often or always $(p=0.148)$ (Table 5$)$. In addition, the confirmation of treatment intention was most commonly performed when a new treatment was considered for all participants, followed by the time of disease progression. Among all healthcare providers, surgeons were the ones who most frequently confirmed patients' intentions. In the treatment intention content confirmed to the patient, the selection of treatment was the most frequent for all participants $-80-90 \%$. This was followed by the progress in disease prediction. The patients' values were ascertained by $72(58.1 \%)$ intensivists, 27 (45.8\%) 


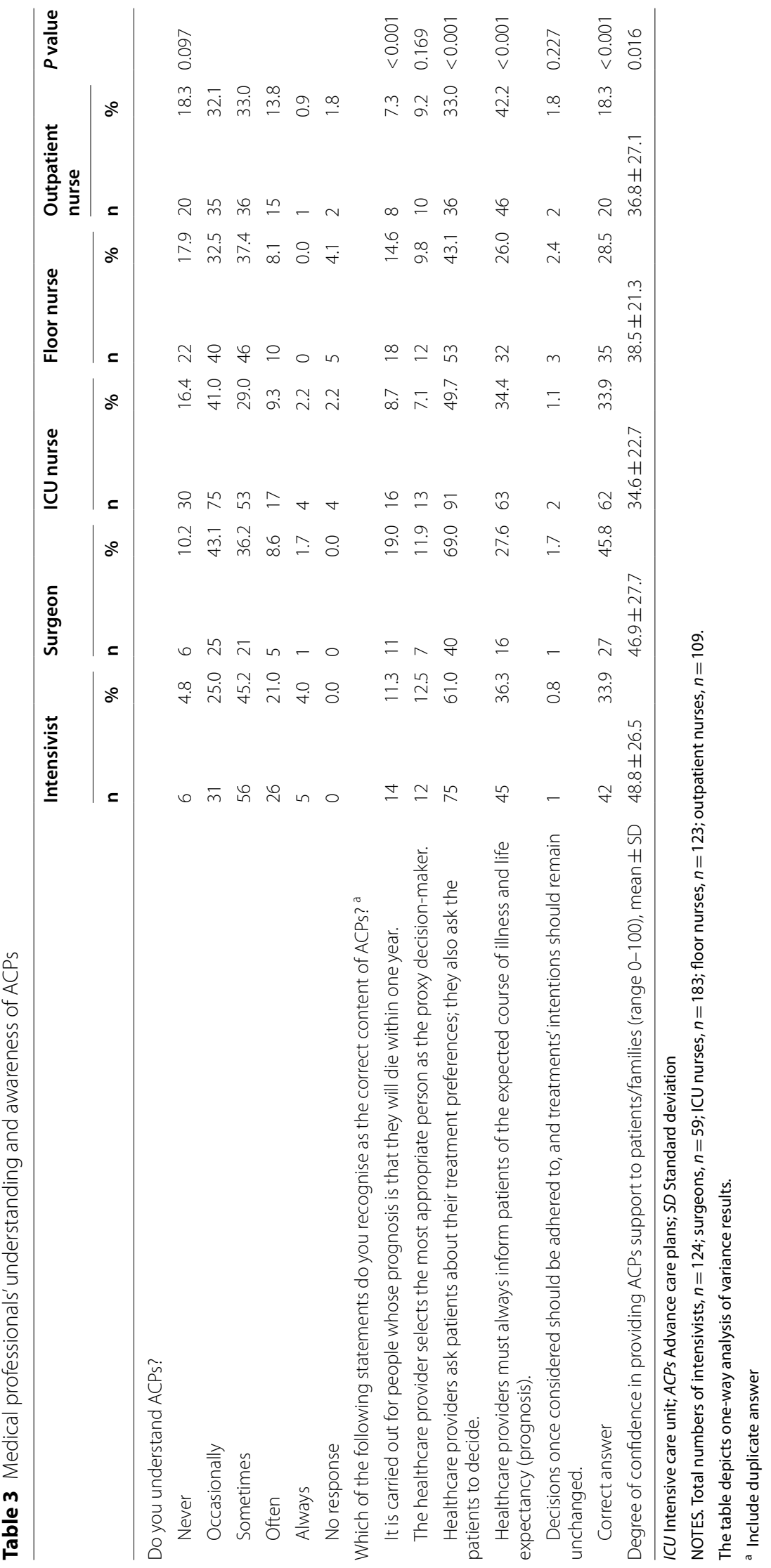


Table 4 Results of discussing DNAR with critical care patients

\begin{tabular}{|c|c|c|c|c|c|c|c|c|c|c|c|}
\hline & \multicolumn{2}{|c|}{ Intensivist } & \multicolumn{2}{|c|}{ Surgeon } & \multicolumn{2}{|c|}{ ICU nurse } & \multicolumn{2}{|c|}{ Floor nurse } & \multicolumn{2}{|c|}{ Outpatient nurse } & \multirow[t]{2}{*}{$P$ value } \\
\hline & $\mathbf{n}$ & $\%$ & $\mathbf{n}$ & $\%$ & n & $\%$ & $\mathbf{n}$ & $\%$ & $\mathbf{n}$ & $\%$ & \\
\hline Do you check DNAR with a patient? & & & & & & & & & & & 0.080 \\
\hline Never & 33 & 26.6 & 27 & 45.8 & 84 & 45.9 & 30 & 24.4 & 46 & 42.2 & \\
\hline Occasionally & 47 & 37.9 & 16 & 27.1 & 52 & 28.42 & 30 & 24.4 & 35 & 32.1 & \\
\hline Sometimes & 24 & 19.4 & 8 & 13.6 & 25 & 13.66 & 31 & 25.2 & 16 & 14.7 & \\
\hline Often & 15 & 12.1 & 6 & 10.2 & 16 & 8.743 & 22 & 17.9 & 10 & 9.2 & \\
\hline Always & 5 & 4.0 & 2 & 3.4 & 5 & 2.732 & 10 & 8.1 & 0 & 0.0 & \\
\hline Non response & 4 & 3.2 & 0 & 0.0 & 1 & 0.546 & 0 & 0.0 & 4 & 3.7 & \\
\hline \multicolumn{12}{|l|}{ Timing $^{a}$} \\
\hline Admitted in the ICU & 40 & 32.3 & 7 & 11.9 & 49 & 26.8 & 0 & 0.0 & 0 & 0.0 & \\
\hline When condition worsens & 69 & 55.6 & 25 & 42.9 & 89 & 48.6 & 96 & 78.0 & 65 & 59.6 & \\
\hline Do not check with the patient & 17 & 13.7 & 15 & 25.4 & 54 & 29.5 & 17 & 13.8 & 3 & 2.8 & \\
\hline At the time of hospital admission & 39 & 31.5 & 6 & 10.2 & 40 & 21.9 & 33 & 26.8 & 18 & 16.5 & \\
\hline During the first outpatient visit & 0 & 0.0 & 0 & 0.0 & 0 & 0.0 & 19 & 15.4 & 6 & 5.5 & \\
\hline Other & 9 & 7.3 & 3 & 5.1 & 14 & 7.7 & 4 & 3.3 & 13 & 11.9 & \\
\hline $\begin{array}{l}\text { Do you recheck DNAR when the } \\
\text { patient'scondition improves? }\end{array}$ & & & & & & & & & & & 0.086 \\
\hline Never & 20 & 16.1 & 12 & 22.2 & 21 & 11.5 & 51 & 41.5 & 52 & 47.7 & \\
\hline Occasionally & 49 & 39.5 & 19 & 35.2 & 53 & 29.0 & 34 & 27.6 & 24 & 22.0 & \\
\hline Sometimes & 21 & 16.9 & 12 & 22.2 & 47 & 25.7 & 24 & 19.5 & 14 & 12.8 & \\
\hline Frequently & 24 & 19.4 & 4 & 7.4 & 40 & 21.9 & 8 & 6.5 & 7 & 6.4 & \\
\hline Absolutely & 8 & 6.5 & 7 & 13.0 & 13 & 7.1 & 4 & 3.3 & 1 & 0.9 & \\
\hline No response & 2 & 1.6 & 5 & 8.5 & 9 & 4.9 & 2 & 1.6 & 10 & 9.2 & \\
\hline \multicolumn{12}{|c|}{ Who decides on selecting surrogate decision-maker? ${ }^{\text {a }}$} \\
\hline Intensivists & 22 & 17.7 & 7 & 11.9 & 9 & 4.9 & 1 & 0.8 & 0 & 0.0 & $<0.001$ \\
\hline Surgeons & 67 & 54.0 & 28 & 47.5 & 35 & 19.1 & 17 & 13.8 & 34 & 31.2 & $<0.001$ \\
\hline ICU nurses & 33 & 26.6 & 16 & 27.1 & 32 & 17.5 & 3 & 2.4 & 0 & 0.0 & $<0.001$ \\
\hline Patients & 41 & 33.1 & 23 & 39.0 & 58 & 31.7 & 87 & 70.7 & 76 & 69.7 & 0.127 \\
\hline Patients'families & 91 & 73.4 & 43 & 72.9 & 166 & 90.7 & 103 & 83.7 & 72 & 66.1 & $<0.001$ \\
\hline Floor nurses & 0 & 0.0 & 0 & 0.0 & 0 & 0.0 & 0 & 0.0 & 14 & 12.8 & \\
\hline Outpatient nurses & 0 & 0.0 & 0 & 0.0 & 0 & 0.0 & 0 & 0 & 18 & 16.5 & \\
\hline Other & 2 & 1.6 & 1 & 1.7 & 4 & 2.2 & 6 & 5 & 1 & 0.9 & \\
\hline
\end{tabular}

DNAR Do not attempt resuscitation; ICU Intensive care unit

NOTES. Total numbers of intensivists, $n=124$; surgeons, $n=59$; ICU nurses, $n=183$; floor nurses, $n=123$; outpatient nurses, $n=109$.

The table depicts one-way analysis of variance results.

a Include duplicate answer

surgeons, and $71(38.8 \%)$ ICU nurses $(P=0.006)$. Fully 53 (42.7\%) intensivists, 35 (60.4\%) surgeons, and 79 (44.6\%) ICU nurses responded that their treatment always/often reflected the patients' wishes $(p=0.378)$.

Fifty-four (43.9\%) nurses in the surgical ward reported that they often or always considered their patients' values and wishes regarding treatment (Table 6). In addition, 80 (65.0\%) floor nurses reported that they often or always shared information on their patients' needs across wards. However, 53 (43.1\%) participating floor nurses reported that they shared their patients' needs, as well as the process that led to the decision, and $20(18.3 \%)$ nurses in the surgical outpatient department responded that they frequently shared patient information with the floor in which the patients were admitted. Further, 73 (67.0\%), $51(46.8 \%)$, and $50(45.9 \%)$ participants said they shared information on the surrogate decision-maker, contents of informed consent, and values and wishes of the patients regarding treatment, respectively.

\section{Discussion}

In the current study, $40 \%$ of the target hospitals provided ACP support to ICU patients, making it a significant addition to the literature which has few studies that 
Table 5 Confirmation of the treatment preferences of patients in ICUs

\begin{tabular}{|c|c|c|c|c|c|c|c|}
\hline & \multicolumn{2}{|c|}{ Intensivist } & \multicolumn{2}{|c|}{ Surgeon } & \multicolumn{2}{|c|}{ ICU nurse } & \multirow[t]{2}{*}{$P$ value } \\
\hline & $\mathrm{n}$ & $\%$ & $\bar{n}$ & $\%$ & $\mathrm{n}$ & $\%$ & \\
\hline Do you confirm the patient's intention regarding treatment? & & & & & & & 0.143 \\
\hline Never & 13 & 10.5 & 4 & 6.8 & 12 & 6.6 & \\
\hline Occasionally & 44 & 35.5 & 25 & 42.4 & 58 & 31.7 & \\
\hline Sometimes & 34 & 27.4 & 19 & 32.2 & 48 & 26.2 & \\
\hline Often & 20 & 16.1 & 10 & 16.9 & 43 & 23.5 & \\
\hline Always & 12 & 9.7 & 1 & 1.7 & 21 & 11.5 & \\
\hline \multicolumn{8}{|l|}{ When do you confirm the patient's intention regarding treatment? ${ }^{\text {a }}$} \\
\hline On admission to the ICU & 57 & 46.0 & 21 & 18.3 & 69 & 37.7 & \\
\hline When condition worsens & 32 & 25.8 & 9 & 7.5 & 59 & 32.2 & \\
\hline At the time of disease improvement & 79 & 63.7 & 37 & 31.2 & 111 & 60.7 & \\
\hline Before starting a new treatment & 80 & 64.5 & 44 & 38.7 & 126 & 68.9 & \\
\hline Don't check at all & 9 & 7.3 & 1 & 1.1 & 9 & 4.9 & \\
\hline Other & 5 & 4.0 & 3 & 3.2 & 11 & 6.5 & \\
\hline \multicolumn{8}{|l|}{ Who confirms the wish of treatment to the patient? ${ }^{\text {a }}$} \\
\hline Intensivist & 84 & 67.7 & 9 & 15.3 & 70 & 38.3 & \\
\hline Surgeon & 114 & 91.9 & 55 & 93,2 & 165 & 90.2 & \\
\hline ICU nurse & 29 & 23.4 & 10 & 16.9 & 79 & 43.2 & \\
\hline Palliative care team & 8 & 6.5 & 3 & 5.1 & 7 & 3.8 & \\
\hline Other & 2 & 1.6 & 1 & 2 & 7 & 3.8 & \\
\hline \multicolumn{8}{|l|}{ What do you discuss with the patient? ${ }^{a}$} \\
\hline Choice of treatment & 107 & 86.3 & 52 & 88.1 & 159 & 86.9 & 0.784 \\
\hline Patients'values & 72 & 58.1 & 27 & 45.8 & 71 & 38.8 & 0.006 \\
\hline Goal of care & 34 & 27.4 & 8 & 13.6 & 47 & 25.7 & 0.095 \\
\hline Desired place for recover & 35 & 28.2 & 18 & 30.5 & 41 & 22.4 & $<0.001$ \\
\hline Selection of a proxy decision-maker & 31 & 25.0 & 11 & 18.6 & 25 & 13.7 & 0.104 \\
\hline Predicted course of the disease & 100 & 80.6 & 47 & 79.7 & 112 & 61.2 & $<0.001$ \\
\hline Prognosis & 73 & 58.9 & 39 & 66.1 & 63 & 34.4 & $<0.001$ \\
\hline Whether the patient wants to know the prognosis and condition & 42 & 33.9 & 18 & 30.5 & 66 & 36.1 & 0.132 \\
\hline Don't check at all & 5 & 4.0 & 1 & 1.7 & 5 & 2.7 & 0.180 \\
\hline Other & 2 & 1.6 & 0 & 0.0 & 2 & 1.1 & \\
\hline $\begin{array}{l}\text { Can the wishes of the patient regarding treatment be incorporated in } \\
\text { the treatment strategy? }\end{array}$ & & & & & & & 0.378 \\
\hline Never & 0 & 0.0 & 1 & 1.7 & 5 & 2.7 & \\
\hline Occasionally & 17 & 13.7 & 3 & 5.1 & 33 & 18.0 & \\
\hline Sometimes & 50 & 40.3 & 19 & 32.2 & 60 & 32.8 & \\
\hline Often & 48 & 38.7 & 32 & 54.2 & 77 & 42.1 & \\
\hline Always & 5 & 4.0 & 3 & 5.1 & 2 & 1.1 & \\
\hline Non response & 4 & 3.2 & 1 & 1.7 & 6 & 3.3 & \\
\hline
\end{tabular}

ICU Intensive care unit

NOTES. Total numbers of intensivists, $n=124$; surgeons, $n=59$; ICU nurses, $n=189$.

The table depicts one-way analysis of variance results

have clarified the status of ACP support provision to ICU patients. In a survey on physicians involved in the treatment of patients undergoing cardiovascular surgery, most of them in the ICU, $85 \%$ of the physicians considered ADs to be useful, whereas $62 \%$ reported they did not discuss the ADs with their patients out of concern that such discussions might make the patients anxious or afraid [20]. In a Japanese survey on physicians working in palliative care units, $62.6 \%$ of the respondents recommended ADs; however, only approximately $30.3 \%$ assisted with the ADs of their patients [21]. This is because palliative care physicians prefer family-centred to patient-centred 
Table 6 Floor/outpatient nurses' awareness of decision support

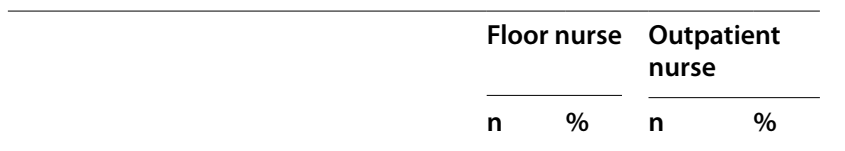

Do you want to discuss with the patients their values and wishes regarding treatment?

$\begin{array}{lllll}\text { Never } & 4 & 3.3 & 26 & 24.1 \\ \text { Occasionally } & 26 & 21.1 & 31 & 28.7 \\ \text { Sometimes } & 39 & 31.7 & 18 & 16.7 \\ \text { Often } & 47 & 38.2 & 28 & 25.9 \\ \text { Always } & 7 & 5.7 & 8 & 7.4\end{array}$

Whether patients' treatment and care needs are shared among wards

$\begin{array}{lll}\text { Never } & 0 & 0.0\end{array}$

$\begin{array}{lll}\text { Occasionally } & 16 & 13.0\end{array}$

Sometimes $\quad 27 \quad 22.0$

$\begin{array}{lll}\text { Often } & 62 & 50.4\end{array}$

$\begin{array}{lll}\text { Always } & 18 & 14.6\end{array}$

Whether patients' treatment and care needs, including decision-making processes, are shared across wards

$\begin{array}{llr}\text { Never } & 6 & 4.9 \\ \text { Occasionally } & 26 & 21.1 \\ \text { Sometimes } & 38 & 30.9 \\ \text { Often } & 48 & 39.0 \\ \text { Always } & 5 & 4.1\end{array}$

Patients' information shared among outpatients' and inpatients' wards

Process leading to the patient's deci- $\quad 41 \quad 38.0$ sion to receive treatment

Informed consent $\quad 51 \quad 47.2$

$\begin{array}{lll}\text { Surrogate decision-makers } & 73 & 67.6\end{array}$

$\begin{array}{lll}\text { The course of treatment } & 24 & 22.2\end{array}$

Patient's treatment wishes and values $\quad 50 \quad 46.3$

Other $\quad 9 \quad 8.3$

Whether the patient's wishes regarding treatment are included in the information provided by other hospitals and facilities

$\begin{array}{lll}\text { Never } & 12 & 10.8 \\ \text { Occasionally } & 38 & 34.2 \\ \text { Sometimes } & 36 & 32.4 \\ \text { Often } & 20 & 18.0 \\ \text { Always } & 0 & 0.0\end{array}$

Does the hospital share information on its patients' wishes regarding treatment from other hospitals or facilities?

$\begin{array}{lll}\text { Never } & 7 & 6.3 \\ \text { Occasionally } & 21 & 18.9 \\ \text { Sometimes } & 20 & 18.0 \\ \text { Often } & 40 & 36.0 \\ \text { Always } & 17 & 15.3\end{array}$

NOTES. Total numbers of floor nurses, $n=123$; outpatient nurses, $n=109$

decision-making in end-of-life care planning [21]. In general, research on ACP and its effects has been conducted in patients with advanced cancer and in the field of palliative care $[4,22]$, yet ACP is not yet accepted in these fields in Japan. Indeed, although research on ACP and ADs has been conducted for about 30 years, the term "ACP "has only recently come into common use and is not widely recognized by the Japanese public. Furthermore, in Japanese culture, patients, including their families, make decisions rather than focusing on self-determination as in Europe and America. Further, support for ACP in ICU-treated patients is still under study, and relevant research has not yet revealed any definite effects. One reason why ACP support is not actively provided to critical care patients is that healthcare providers have only a low understanding of ACP. The current study confirmed this understanding by revealing that many respondents across job categories and departments did not completely understand ACP. Previous studies indicated that although they understood the necessity of ACP support for high-risk postsurgical and ICU-treated patients, they were aware of a lack of knowledge and skills to support ACP [23, 24]. The current study provides the same result and emphasises the importance of improving healthcare providers' recognition and understanding of ACP in the future.

In addition, the proportion of healthcare providers who confirmed DNAR with patients ranged from 10 to $20 \%$, and those who did not reconfirm DNAR following improvement in patients' conditions ranged from 10 to $50 \%$. According to the literature, the extent to which patients are involved in DNAR decision-making varies widely from $25 \%$ [25] to $82 \%$ [26]. Even this involvement is often complicated by various factors, such as cultural aspects, situation, hospital policy, and individual behaviour [27]. In particular, surgical ward nurses and outpatient nurses tended not to reconfirm their intentions regarding DNAR. Very often, DNAR was checked with patients only after their condition worsened. These findings suggest that a patient's recovery may reduce the need for ACP and weaken the perception that patients want to be treated. Further, the literature reveals preferences regarding end-of-life care change for patients who recover after ICU treatment [28], as healthcare providers find it challenging to continue the discussion on patient preferences over the course of the treatment [7].

In addition, approximately $30 \%$ of the intensivists, surgeons, and ICU nurses answered that patients would select a surrogate decision-maker, and, participants exclude outpatient nurses, the surrogate was selected by family members. The ACP discussion process includes the selection of a surrogate decision-maker but it is not sufficiently done in practice; therefore, it is often too late to ask the patient for a surrogate decision-maker, since the confirmation of the patient's intention to undergo treatment is generally made at the time of rapid disease progression. Moreover, in some cases, a healthcare 
provider selects a surrogate decision-maker. In principle, the selector of surrogate decision-makers is the patient. Critically ill patients may not be able to participate in decision-making in that they often lack decision-making capacity. However, this result has possibilities indicating that they may not understand how to conduct ACP [23, 24].

It may be unclear who will support or discuss the ACP with patients [29]. Some patients also do not have a surrogate. With rapid aging in the developed world, healthcare providers have more opportunities to practice end-of-life care and thus examine and address patients' best interests. Studies evaluating the effectiveness of established $\mathrm{ACP}$ interventions point out that the processes, interventions, and metrics of the caregivers about ACP are inconsistent and very complex [30]. However, the ACP may share a patient's treatment wishes and requirements with a healthcare provider or a surrogate decision-maker and are worth being discussed and addressed in advance for critical care patients at high risk of losing their decisionmaking capacity.

Patients who have undergone high-risk surgery and have been admitted to ICUs show willingness to discuss ACP in advance to ensure that their treatment preferences are respected and to minimise the burden on family members toward the end of their life [28]. At the same time, an increasing number of healthcare providers are positively considering the provision of ACPs support to patients $[21,31]$. Therefore, in the future, the provision of ACP support to critical care patients may be positively promoted by improving healthcare providers' knowledge and support skills. Only approximately $20-30 \%$ of ICUs and $40 \%$ of wards and outpatients considered patients' wishes and values regarding treatment and implemented processes that realised these wishes and decisions. Further, in acute-care hospitals, especially when patients experience rapid changes in their disease conditions, their wishes regarding treatment/care and resuscitation might differ from those recorded on admission [32, 33]. In many cases, patients and physicians do not discuss resuscitation, and the associated needs of less than half the total number of patients are absent in medical records [34]. Such incidents suggest that shared decision- making processes involving physicians, patients, and healthcare providers are inadequate, raising the concern that such decision-making increases the likelihood of patients receiving unwanted treatment, as well.

Acute-care hospitals experience difficulties in deciding when and by whom their patients' intentions should be confirmed because the length of hospitalization is short, even for patients undergoing high-risk surgeries, and it is challenging for healthcare providers to identify the intentions of patients in severe conditions [35]. Those who receive critical care are more likely to move to the end of life than those who do not [34]. If patients enter end-of-life, they should be provided high-quality medical care that satisfies their preferences. It is necessary to ask the patients to elucidate their wishes regarding treatment and sense of value in advance at the time of hospitalization or starting treatment to initiate ACP support provision [36, 37]. Instead of focusing only on end-of-life care, ACPs should encompass patients receiving all types of treatment. Many of the outcomes of ACP studies are completion of $\mathrm{ADs}$ and reduction in ICU admissions $[22,38]$. In Japan, because the documentation of ACP and patients' treatment preferences is not regulated, it may not be essential for patients to document ACP. Even without documentation, surrogate decisions can be made based on presumptive intent if the surrogate decisionmaker or healthcare provider understands the patient's wishes for treatment. To respect patient autonomy, the first step is to create an opportunity for patients receiving critical care to talk to family members and healthcare providers about their values and way of life.

This study has some limitations. First, the sample size of surgeons considered in this study was small. The response rate was as low at 30\% for all respondents except intensivists. Second, although it was planned to investigate the status of ACP support for each job category as well as each hospital's response, it was challenging to secure the participation of all the healthcare providers of a single hospital, which has not been adequately factored in. In addition, because ADs, designation of a surrogate decision-maker are not determined by the law in Japan, it is not always possible to observe the intentions behind ADs and DNARs; this may also be a factor in the study's results. These are limits to the generalizability of our findings. By examining patients' perceptions of ACP support from various roles involved in the care of patients receiving ICU treatment, future studies may help overcome the challenges in promoting ACP support.

\section{Conclusions}

The study found that $40 \%$ of the target acute-care hospitals undertook provision of ACP support to patients receiving critical care, suggesting that most healthcare professionals lack appropriate understanding of the importance of ACP and that, in general, ACP is initiated very late after ICU admission. Further, the perception of ACP differs among healthcare providers and ACP remains an ambiguous concept. In acute-care hospitals where patients receive different kinds of treatment or the physicians who make treatment decisions change frequently, it is necessary to confirm and connect the changing feelings and thoughts of patients' family members and healthcare providers regarding the 
treatment and care provided. These findings suggest the need to develop processes that consider patients' wishes and decisions regarding treatment, records that help transition values, early education programs targeting patients, and appropriate supporters.

\section{Abbreviations}

ACP: Advance care planning; AD: Advance directive; DNAR: Do not attempt resuscitation.

\section{Supplementary Information}

The online version contains supplementary material available at https://doi. org/10.1186/s12904-021-00900-5.

\section{Additional file 1.}

\section{Acknowledgements}

The authors wish to thank the healthcare providers who participated in this study.

\section{Authors' contributions}

KY performed research design, data collection, the analysis and interpretation of results, and manuscript preparation. YY and KN contributed to the research idea and designed, analysed, and interpreted the results; advised the whole research process; and helped prepare the manuscript. All authors read and approved the final manuscript.

\section{Funding}

This work was supported by JSPS KAKENHI (grant number: JP19K19613). The funding source had no role in the design or conduct of the study, data collection, management, analysis, or approval of the manuscript.

\section{Availability of data and materials}

The datasets used and/or analysed during the current study are available from the corresponding author on reasonable request.

\section{Declarations}

\section{Ethics approval and consent to participate}

The study was approved by ethics committees at St. Luke's International University (approval number: 19-A036) and conducted following the Declaration of Helsinki guidelines. Participants were provided written explanations of the survey's purpose, research methods used, details of participating in and withdrawing from the survey, protection of personal information, and data management methods used in the study. The collected data were managed separately, and facility ID numbers and a correspondence table were created to ensure that individual participants could not be identified from the data. Further, data such as basic attributes were coded to maintain participant anonymity. Since participation was anonymous and voluntary, consent was implicitly obtained by receipt of completed questionnaires.

\section{Consent for publication}

Not applicable.

\section{Competing interests}

The authors declare that they have no competing interests.

\section{Author details}

${ }^{1}$ Department of Critical Care Nursing, Graduate School of Nursing Science, St. Luke's International University, 10-1, Akashi-cho, Tokyo, Japan. ${ }^{2}$ Department of Nursing Informatics, Graduate School of Nursing Science, St. Luke's International University, 10-1, Akashi-cho, Tokyo, Japan.
Received: 14 August 2021 Accepted: 24 December 2021

Published online: 07 January 2022

\section{References}

1. Sudore RL, Fried TR. Redefining the "planning" in advance care planning: preparing for end-of-life decision making. Ann Intern Med. 2010;153(4):256-61. https://doi.org/10.7326/0003-4819-153-4-20100 8170-00008.

2. The Japanese Society of Intensive Care Medicine: Guidelines for end-oflife care in emergency and intensive care. https://www.jsicm.org/publi cation/3gakkai teigen1411.html. Accessed 24 Dec 2021.

3. Chan HY, Ng JS, Chan KS, Williamson F, Dormer S, Wilkinson A, et al. Effects of a nurse-led post-discharge advance care planning programme for community-dwelling patients nearing the end of life and their family members: a randomised controlled trial. Int J Nurs Stud. 2018;87:26-33. https://doi.org/10.1016/j.jinurstu.2018.07.008.

4. Sinclair C, Auret KA, Evans SF, Williamson F, Dormer S, Wilkinson A, et al. Advance care planning uptake among patients with severe lung disease: a randomised patient preference trial of a nurse-led, facilitated advance care planning intervention. BMJ Open. 2017;7(2):e013415. https://doi. org/10.1136/bmjopen-2016-013415.

5. Orazem M, Groselj U, Stojan M, Majdic N, Vidmar G, Grosek S. End-of-life decisions in 34 Slovene intensive care units: a nationwide prospective clinical study. Minerva Anestesiol. 2017;83(7):728-36. https://doi.org/10. 23736/S0375-9393.17.11711-6.

6. Köstenberger M, Diegelmann S, Terlutter R, Bidmon S, Neuwersch S, Likar R. Advance directives in Austrian intensive care units: an analysis of prevalence and barriers. Resusc Plus. 2020;3:100014. https://doi.org/10. 1016/j.resplu.2020.100014.

7. Quenot JP, Ecarnot F, Meunier-Beillard N, Dargent A, Large A, Andreu P, et al. What are the ethical questions raised by the integration of intensive care into advance care planning? Ann Transl Med. 2017;5(Suppl 4):S46. https://doi.org/10.21037/atm.2017.08.08.

8. Gibbins J, McCoubrie R, Alexander N, Kinzel C, Forbes K. Diagnosing dying in the acute hospital setting — are we too late? Clin Med (Lond). 2009;9(2):116-9. https://doi.org/10.7861/clinmedicine.9-2-116.

9. Hart JL, Harhay MO, Gabler NB, Ratcliffe SJ, Quill CM, Halpern SD. Variability among US intensive care units in managing the care of patients admitted with preexisting limits on life-sustaining therapies. JAMA Intern Med. 2015;175(6):1019-26. https://doi.org/10.1001/jamainternmed.2015. 0372 .

10. Wang AY, Ma HP, Kao WF, Tsai SH, Chang CK. Characteristics and outcomes of "do not resuscitate" patients admitted to the emergency departmentintensive care unit. J Formos Med Assoc. 2019;118(1 Pt 2):223-9. https:// doi.org/10.1016/j.jma.2018.03.016.

11. Kainuma M. Current and future of end-of-life care and palliative care in the intensive care area. ICU\&CCU. 2016;40(11):771-8.

12. Scheunemann LP, Ernecoff NC, Buddadhumaruk P, Carson SS, Hough $\mathrm{CL}$, Curtis JR, et al. Clinician-family communication about patients values and preferences in intensive care units. JAMA Intern Med. 2019;179(5):676-84. https://doi.org/10.1001/jamainternmed.2019.0027.

13. Ethics committee, Japanese Society of Intensive Care Medicine. DNAR (do not attempt resuscitation) order. J Jpn Soc Intensive Care Med. 2017;24(2):210-5.

14. Kim K, Chakravarthy B, Anderson C, Liao S. To intubate or not to intubate: emergency medicine physicians' perspective on intubating critically ill, terminal cancer patients. J Pain Symptom Manag. 2017;54(5):654-660.e1. https://doi.org/10.1016/j.jpainsymman.2017.07.038.

15. Lee $Y L$, Ong YY, Thong SY, Ng SY. A retrospective study of end-of-life care decisions in the critically ill in a surgical intensive care unit. Indian J Palliat Care. 2018;24(1):17-24. https://doi.org/10.4103/IJPC.IJPC_81_17.

16. Choudhuri AH, Sharma A, Uppal R. Effects of delayed initiation of endof-life care in terminally ill intensive care unit patients. Indian J Crit Care Med. 2020;24(6):404-8. https://doi.org/10.5005/jp-journals-10071-23454.

17. Paul Olson TJ, Brasel KJ, Redmann AJ, Alexander GC, Schwarze ML. Surgeon-reported conflict with intensivists about postoperative goals of care. JAMA Surg. 2013;148(1):29-35. https://doi.org/10.1001/jamasurgery. 2013.403. 
18. Sudore RL, Lum HD, You JJ, Hanson LC, Meier DE, Pantilat SZ, et al. Defining advance care planning for adults: a consensus definition from a multidisciplinary Delphi panel. J Pain Symptom Manag. 2017;53(5):821-32.e1. https://doi.org/10.1016/j.jpainsymman.2016.12.331.

19. Ministry of Health, Labour and Welfare: Medical care at the final stage of life: Guidelines for the decision process. https://www.mhlw.go.jp/file/ 04-Houdouhappyou-10802000-Iseikyoku-Shidouka/0000197701.pdf. Accessed 24 Dec 2021.

20. Gigon F, Merlani P, Ricou B. Swiss physicians' perspectives on advance directives in elective cardiovascular surgery. Minerva Anestesiol. 2015;81(10):1061-75.

21. Nakazawa K, Kizawa Y, Maeno T, Takayashiki A, Abe Y, Hamano J, et al. Palliative care physicians' practices and attitudes regarding advance care planning in palliative care units in Japan: a nationwide survey. Am J Hosp Palliat Care. 2014;31(7):699-709. https://doi.org/10.1177/1049909113 507328.

22. Khandelwal N, Kross EK, Engelberg RA, Coe NB, Long AC, Curtis JR. Estimating the effect of palliative care interventions and advance care planning on ICU utilization: a systematic review. Crit Care Med. 2015:43(5):1102-11. https://doi.org/10.1097/CCM.0000000000000852.

23. Blackwood DH, Walker D, Mythen MG, Taylor RM, Vindrola-Padros C. Barriers to advance care planning with patients as perceived by nurses and other healthcare professionals: a systematic review. J Clin Nurs. 2019;28(23-24):4276-97. https://doi.org/10.1111/jocn.15049.

24. Keon-Cohen Z, Myles PS, Story DA. A survey of Australian and New Zealand anaesthetists' attitudes towards resuscitation orders in the perioperative setting. Anaesth Intensive Care. 2017;45(3):396-402. https://doi. org/10.1177/0310057X1704500316.

25. Holland CL, Bowker LK, Myint PK. Barriers to involving older people in their resuscitation decisions: the primary-secondary care mismatch highlights the potential role of general practitioners. Int J Clin Pract. 2013;67(4):379-84. https://doi.org/10.1111/ijcp.12067.

26. Fritz Z, Fuld J, Haydock S, Palmer C. Interpretation and intent: a study of the (mis) understanding of DNAR orders in a teaching hospital. Resuscitation. 2010;81(9):1138-41. https://doi.org/10.1016/j.resuscitation.2010.05. 014.

27. Mockford C, Fritz Z, George R, Court R, Grove A, Clarke B, et al. Do not attempt cardiopulmonary resuscitation (DNACPR) orders: a systematic review of the barriers and facilitators of decision-making and implementation. Resuscitation. 2015;88:99-113. https://doi.org/10.1016/j.resuscitat ion.2014.11.016.

28. Yamamoto K, Yonekura Y, Hayama J, Matsubara T, Misumi H, Nakayama K. Advance care planning for intensive care patients during the perioperative period: a qualitative study. SAGE Open Nurs. 2021;7:23779608211038845. https://doi.org/10.1177/237796082110388 45.

29. Flannery L, Ramjan LM, Peters K. End-of-life decisions in the intensive care unit (ICU) - exploring the experiences of ICU nurses and doctors - a critical literature review. Aust Crit Care. 2016;29(2):97-103. https://doi.org/ 10.1016/j.aucc.2015.07.004.

30. McMahan RD, Tellez I, Sudore RL. Deconstructing the complexities of advance care planning outcomes: what do we know and where do we go? A scoping review. J Am Geriatr Soc. 2021;69(1):234-44. https://doi. org/10.1111/jgs.16801.

31. Yokoya S, Kizawa Y, Maeno T. Practice and perceived importance of advance care planning and difficulties in providing palliative care in geriatric health service facilities in Japan: a nationwide survey. Am J Hosp Palliat Care. 2018;35(3):464-72. https://doi.org/10.1177/1049909117 723859.

32. Esfahani S, Yi C, Madani CA, Davidson JE, Edmonds KP, Wynn S. Exploiting technology to popularize goals-of-care conversations and advance care planning. Crit Care Nurse. 2020;40(4):32-41. https://doi.org/10.4037/ ccn2020576.

33. Taneja R, Sibbald R, Elliott L, Burke E, Bishop KA, Jones PM, et al. Exploring and reconciling discordance between documented and preferred resuscitation preferences for hospitalized patients: a quality improvement study. Can J Anaesth. 2021;68(4):530-40. https://doi.org/10.1007/ s12630-020-01906-y.

34. El-Jawahri A, Mitchell SL, Paasche-Orlow MK, Temel JS, Jackson VA, Rutledge RR, et al. A randomized controlled trial of a CPR and intubation video decision support tool for hospitalized patients. J Gen Intern Med. 2015;30(8):1071-80. https://doi.org/10.1007/s11606-015-3200-2.

35. Toevs CC. Transitioning to comfort-focused Care at the end of life. Surg Clin North Am. 2019;99(5):1019-27. https://doi.org/10.1016/j.suc.2019.06. 014.

36. Ramachenderan J, Auret K. The challenge of perioperative advance care planning. J Pain Symptom Manag. 2019;58(3):538-42. https://doi.org/10. 1016/j.jpainsymman.2019.04.023.

37. Udelsman BV, Govea N, Cooper Z, Chang DC, Bader A, Meyer MJ. Variation in patient-reported advance care preferences in the preoperative setting. Anesth Analg. 2021;132(1):210-6. https://doi.org/10.1213/ANE.00000 00000004617.

38. Houben CHM, Spruit MA, Groenen MTJ, Wouters EFM, Janssen DJA. Efficacy of advance care planning: a systematic review and meta-analysis. J Am Med Dir Assoc. 2014;15(7):477-89. https://doi.org/10.1016/j.jamda. 2014.01.008.

\section{Publisher's Note}

Springer Nature remains neutral with regard to jurisdictional claims in published maps and institutional affiliations.

Ready to submit your research? Choose BMC and benefit from:

- fast, convenient online submission

- thorough peer review by experienced researchers in your field

- rapid publication on acceptance

- support for research data, including large and complex data types

- gold Open Access which fosters wider collaboration and increased citations

- maximum visibility for your research: over $100 \mathrm{M}$ website views per year

At BMC, research is always in progress.

Learn more biomedcentral.com/submissions 